\title{
Evaluation of the Risk of Clinical Deterioration among Inpatients with COVID-19
}

\author{
Víctor O. Costa $\left(D,{ }^{1}\right.$ Eveline M. Nicolini, ${ }^{2}$ Bruna M. A. da Costa $\left(D,{ }^{3}\right.$ Fabrício M. Teixeira $\left(\mathbb{D},{ }^{1}\right.$ \\ Júlia P. Ferreira $\mathbb{D}^{1},{ }^{1}$ Marcos A. Moura, ${ }^{4}$ Jorge Montessi, ${ }^{2}$ Rogério L. Campos, ${ }^{5}$ \\ Andrea N. Guaraldo, ${ }^{6}$ and Patrícia M. Costa ${ }^{7}$
}

\author{
${ }^{1}$ Medicine, Faculdade de Ciências Médicas e da Saúde de Juiz de Fora-SUPREMA, Juiz de Fora 36033-003, Brazil \\ ${ }^{2}$ Thoracic Surgery, Hospital Monte Sinai, Juiz de Fora 36033-318, Brazil \\ ${ }^{3}$ Nursing, Faculdade de Ciências Médicas e da Saúde de Juiz de Fora-Suprema, Juiz de Fora 36033-003, Brazil \\ ${ }^{4}$ Infectology, Faculdade de Ciências Médicas e da Saúde de Juiz de Fora-Suprema, Juiz de Fora 36033-003, Brazil \\ ${ }^{5}$ Psychiatrist and Emergency, Hospital Monte Sinai, Juiz de Fora 36033-318, Brazil \\ ${ }^{6}$ Intensive Therapy, Hospital Monte Sinai, Juiz de Fora 36033-318, Brazil \\ ${ }^{7}$ Intensive Therapy and Dermatology Hospital Monte Sinai, Juiz de Fora 36033-318, Brazil
}

Correspondence should be addressed to Víctor O. Costa; victordeoliveiracosta82@gmail.com

Received 27 December 2020; Revised 19 May 2021; Accepted 12 June 2021; Published 29 June 2021

Academic Editor: Jay C. Brown

Copyright (C) 2021 Víctor O. Costa et al. This is an open access article distributed under the Creative Commons Attribution License, which permits unrestricted use, distribution, and reproduction in any medium, provided the original work is properly cited.

\begin{abstract}
This study aims to assess the risk of severe forms of COVID-19, based on clinical, laboratory, and imaging markers in patients initially admitted to the ward. This is a retrospective observational study, with data from electronic medical records of inpatients, with laboratory confirmation of COVID-19, between March and September 2020, in a hospital from Juiz de Fora-MG, Brazil. Participants $(n=74)$ were separated into two groups by clinical evolution: those who remained in the ward and those who progressed to the ICU. Mann-Whitney $U$ test was taken for continuous variables and the chi-square test or Fisher's exact test for categorical variables. Comparing the proposed groups, lower values of lymphocytes $(p=<0.001)$ and increases in serum creatinine $(p=0.009)$, LDH $(p=0.057)$, troponin $(p=0.018)$, IL-6 $(p=0.053)$, complement C4 $(p=0.040)$, and CRP $(p=0.053)$ showed significant differences or statistical tendency for clinical deterioration. The average age of the groups was $47.9 \pm 16.5$ and $66.5 \pm 7.3$ years $(p=0.001)$. Hypertension $(p=0.064)$, heart disease $(p=0.048)$, and COPD $(p=0.039)$ were more linked to ICU admission, as well as the presence of tachypnea on admission $(p=0.051)$. Ground-glass involvement $>25 \%$ of the lung parenchyma or pleural effusion on chest CT showed association with evolution to ICU $(p=0.027)$, as well as bilateral opacifications $(p=0.030)$ when compared to unilateral ones. Laboratory, clinical, and imaging markers may have significant relation with worse outcomes and the need for intensive treatment, being helpful as predictive factors.
\end{abstract}

\section{Introduction}

First detected in December 2019, COVID-19 caused by the new coronavirus (SARS-CoV-2) has been considered a pandemic by the World Health Organization (WHO) [1]. According to data from the Ministry of Health (MS), of September 2020, 4,717,991 cases have already been detected in Brazil, of which 141,406 have died, resulting in a lethality rate of 3\% [2]. On a global scale, the country is the third with the highest number of accumulated cases and the second in the number of deaths, only behind the United States [3].

COVID-19 can be clinically manifested in three ways, $80 \%$ of patients are asymptomatic or oligosymptomatic with mild symptoms without complications (fever, dry cough, fatigue, without pneumonia, or with mild pneumonia), $15 \%$ progress to hospitalization with moderate symptoms and need for oxygen therapy (tachypnea, drop in oxygen saturation in room air, and signs of respiratory distress), and 5\% have the severe form (severe acute respiratory insufficiency 
(ARDS), septic shock, and multiple organ dysfunction) with an indication for treatment in the intensive care unit (ICU) $[1,4]$.

In the group of patients requiring hospitalization or ICU, studies suggest possible predictive factors for worse clinical evolution, which would indicate a higher risk of developing ARDS and/or death [5-7]. Up to the Epidemiological Week Bulletin 38, of September 2020, more than 730,000 cases of ARDS hospitalized in Brazil were reported, $53.2 \%$ by COVID-19, with a lethality rate of $34.4 \%$ [8]. These data corroborate to emphasize the importance of establishing clinical, laboratory, and imaging predictors for a worse prognosis in order to assist in the early recognition of patients at risk.

Thus, the present study aims to assess the risk of severe forms of COVID-19, based on clinical signs, laboratory tests, and computed tomography of patients who were initially in the hospitalization unit.

\section{Methods}

2.1. Design, Ethical Aspects, and Procedures. This is a retrospective observational study. The data were collected by the researchers through electronic medical records of patients who were conducted at the Institute of Clinics and Surgeries of Juiz de Fora-Monte Sinai Hospital in the city of Juiz de Fora, Minas Gerais, Brazil. Such hospital has regional coverage in the Zona da Mata of Minas Gerais, with a population of approximately two million inhabitants. The collection was made between March 2020 and August 2020. The research stages began only after approval by the Research Ethics Committee (Opinion no. 4,080,157, Santa Casa de Misericórdia de Juiz de Fora/MG). After collecting information from electronic medical records, data were tabulated using Google Forms. After correction of typing errors, data analysis was conducted.

2.2. Participants. The study included all patients who were admitted to the ward sector with symptoms of COVID-19. Inclusion criteria were as follows: patients of any age, nonpregnant, with COVID-19, confirmed by specific laboratory test-RT-PCR. Exclusion criteria were as follows: patients who were not positive for the RT-PCR laboratory exam for COVID-19. In addition, patients whose medical reports were not clear by inappropriate filling were excluded from the data. In the end, 74 participants were included in the study. No patient who participated in the research had received vaccine for COVID-19, given the time when the research was carried out.

For admission to the ICU, the criteria were as follows: acute respiratory failure (no improvement in oxygen saturation, despite the $\mathrm{O}_{2}$ supply $\left(\mathrm{Sat} \mathrm{O}_{2}<93 \%\right.$ with $6 \mathrm{~L} / \mathrm{min}$ supply); acute respiratory failure with the need for invasive mechanical ventilation (need for $\mathrm{FiO}_{2}>50 \%$ for $\mathrm{SpO}_{2}$ mentor $>94 \%$ or a respiratory rate less than or equal to 24 , $\mathrm{PaCO}_{2}>$ or equal to $50 \mathrm{mmHg}$ and $\mathrm{pH}<$ or equal to 7.35 , and $\mathrm{PaO}_{2} / \mathrm{FiO}_{2}$ ratio $<200$ ); sepsis or septic shock with hypotension (SBP $<90$ or MAP <65) and/or signs of tissue hypoperfusion (elevated lactate); and acute organ dysfunctions (acute renal failure, altered level of consciousness, liver failure, etc.)

All patients who participated in the study were initially admitted to the ward, where laboratory tests were performed within the first 72 hours. Depending on the clinical evolution, patients were separated into two groups: those who remained in the ward and those who progressed to the ICU. It is important to note that laboratory tests were performed in the first 72 hours in order to verify predictive factors for admission to the ICU, and the same number of tests was not performed later.

2.3. Data Analysis. Continuous variables were expressed as means \pm SDs, while categorical variables were summarized as numbers (\%). Differences between the characteristics of the result groups were assessed using the Mann-Whitney $U$ test for continuous variables and chi-square tests or Fisher's exact test for categorical variables. $p<0.05$ was considered statistically significant. All data were analyzed using SPSS (20.0.0 IBM SPSS).

\section{Results}

The general demographic and epidemiological characteristics of all patients are summarized in Table 1. The individuals who had hospitalization and did not progress to the ICU were compared with those who progressed to the ICU, in order to assess criteria that can be observed, verifying the evolution of the patient to the ICU. The number of patients who did not progress to the ICU was 59, while 15 progressed to the ICU, six of whom died. The average age among patients admitted to the ward was $47.9( \pm S D: 165)$ and 66.5 among patients who progressed to the ICU ( \pm SD: 173$)$, with a significant difference in relation to the patient's age ( $p=0.001$ ), showing that older age qualifies the patient to be admitted to the ICU. There was no statistically significant difference regarding the ethnic group $(p=0.696)$, being a health professional $p=0.276)$, having received the flu vaccine in the last campaign $(p=0.488)$, or having had contact with someone who is sick, that is, individuals with the flu syndrome $(p=0.741)$. In addition, the number of patients who were not residents of the city Juiz de Fora, Minas Gerais, Brazil, proved to be significant with six $(8.1 \%)$, with a trend of difference between groups $(p=0.077)$. Regarding comorbidities, hypertension $(p=0.064)$, heart disease $(p=0.048)$, and COPD $(p=0.039)$ were more linked to ICU admission. The number of patients with COPD was few, but they were shown to have statistical relevance. As far as hypertension is concerned, it tends to show statistical differences between the groups.

Regarding the symptoms that the patient reported feeling before hospital admission, the presence of odynophagia was a minor factor in patients who will progress to the ICU $(p=0.016)$ since none $(0.0 \%)$ reported to have presented with such symptoms on admission. Tachypnea at the time of care at the hospital, on the other hand, presented a significant link with future ICU admission $(p=0.051)$. 
TABLE 1: Demographic data of the studied sample.

\begin{tabular}{|c|c|c|c|}
\hline & \multicolumn{2}{|c|}{ Place of hospitalization } & \multirow{2}{*}{$p$ value } \\
\hline & Hosp_Intern $(n=59)$ & ICU $(n=15)$ & \\
\hline \multicolumn{4}{|l|}{ Descriptive data } \\
\hline Age & $47.9( \pm$ SD:16.5) & $66.5( \pm S D: 17.3)$ & 0.001 \\
\hline Sex (male) & $35(47.3)$ & $12(16.2)$ & 0.137 \\
\hline White ethnicity & $40(70.1)$ & $9(15.7)$ & 0.696 \\
\hline Patient is a healthcare professional (yes) & $13(18.0)$ & $1(1.3)$ & 0.276 \\
\hline Patient had contact with grippal syndrome (yes) & $24(32.4)$ & $4(5.4)$ & 0.741 \\
\hline Received flu vaccine during the last campaign (yes) & $21(42.8)$ & $6(12.2)$ & 0.488 \\
\hline Not being a resident of the city (Juiz de Fora) & $10(13.5)$ & $6(8.1)$ & 0.077 \\
\hline \multicolumn{4}{|l|}{ Comorbidities } \\
\hline Hypertension & $20(27.0)$ & $9(12.2)$ & 0.064 \\
\hline Diabetes & $4(5.4)$ & $0(0.0)$ & 0.300 \\
\hline Dyslipidemia & $0(0.0)$ & $1(1.4)$ & 0.203 \\
\hline Immunosuppression & $2(2.7)$ & $0(0.0)$ & 0.470 \\
\hline Cardiopathy & $4(5.4)$ & $4(5.4)$ & 0.048 \\
\hline Asthma & $1(1.4)$ & $0(0.0)$ & 1.000 \\
\hline COPD & $0(0.0)$ & $2(2.7)$ & 0.039 \\
\hline \multicolumn{4}{|l|}{ Symptoms on admission } \\
\hline Tachypnea & $45(62.5)$ & $7(9.7)$ & 0.051 \\
\hline Tachycardia & $12(16.6)$ & $3(4.1)$ & 0.929 \\
\hline Cough & $47(63.5)$ & $9(12.2)$ & 0.175 \\
\hline Dyspnea & $21(28.4)$ & $6(8.1)$ & 0.752 \\
\hline Odynophagia & $17(23.0)$ & $0(0.0)$ & 0.016 \\
\hline Sputum production & $1(1.4)$ & $1(1.4)$ & 0.367 \\
\hline Headache & $13(17.6)$ & $2(2.7)$ & 0.791 \\
\hline Fever & $44(59.5)$ & $10(13.5)$ & 0.531 \\
\hline Rhinorrhea & $14(18.9)$ & $2(2.7)$ & 0.499 \\
\hline Diarrhea & $13(17.6)$ & $3(4.1)$ & 0.864 \\
\hline
\end{tabular}

SD: standard deviation; $n$ (\%); $p$ values were calculated by the Mann-Whitney $U$ test, $\chi 2$ test, or Fisher's exact test.

With regard to radiographic parameters, a statistical comparison was made between patients at the time of admission and at the time of discharge, in order to verify the change in the radiographic pattern as a discharge criterion. Inpatients underwent chest computed tomography (CT) at the time of admission to the hospital and at discharge. The number of patients with ground-glass involvement $>50 \%$ is four $(6.9 \%)$ on admission and 16 (27.6\%) with involvement between 25 and $50 \%$ of the lung. At discharge, in the analyzed patients, $12(29.2 \%)$ had an occupation of $25-50 \%$ of the lungs and nine (21.9\%) had an impairment $>50 \%$ (Table 2).

Regarding laboratory evaluation, patients were analyzed in various parameters, comparing laboratory tests of hospitalized patients who did not progress to the ICU with laboratory tests of those who progressed to the ICU. In the hospital internment group, there are only patients who were admitted and did not go to the ICU. All examinations were performed until the third day of hospitalization, in order to assess the patient's prognosis.

Comparing individuals admitted to the ICU with those not admitted, it was evident that the lowest lymphocyte count $(768.4 \pm 340.4 ; p=<0.001)$, the highest serum creatinine value $(1.73 \pm 1.68 ; p=0.009)$, and higher values of lactate dehydrogenase $(\mathrm{LDH})(730.3 \pm 307.6 ; p=0.057)$, troponin $(18.7 \pm 26.9 ; p=0.018)$, interleukin-6 $(45.1 \pm 32.2$; $p=0.053)$, C4 complement $(52.4 \pm 12.6 ; p=0.040)$, and
C-reactive protein (CRP) $(102.6 \pm 93.7 ; p=0.053)$ showed significant differences or statistical tendency when we compared individuals who progressed to the ICU with those who did not (Table 3).

Finally, a comparison of medication usage and radiographic condition at admission was made with the prediction of the patient to progress to the ICU. Regarding the medications used, they were compared in order to verify whether their early use would have an influence on the patient's evolution to the ICU (Table 4). These medications refer to medications that patients used before hospitalization. It was found that most patients using ivermectin 11 (18.9\%) progressed to the ICU $(p=0.056)$. On the other hand, with the involvement of ground glass in greater extent or the presence of pleural effusion with the other findings on CT, there is a positive association for the patient's evolution to the ICU $(p=0.027)$, as well as the comparison between those who presented bilateral opacifications with those who had unilateral opacifications $(p=0.030)$. The number of hospitalization days in patients who did not progress to the ICU was $6.2 \pm 2.7$ and in those who progressed to the ICU was $10.7 \pm 8.7$ and notably showed a difference in the comparison between the groups $(p=<0.001)$. It is important to note that the number of days of hospitalization addresses every day that the patient was in the hospital, including the infirmary and then his evolution to the ICU. 
TABLe 2: Chest CT results.

\begin{tabular}{|c|c|c|c|c|}
\hline & \multicolumn{4}{|c|}{ Admission $(n=73)$} \\
\hline & $n(\%)$ & Involvement $<25 \%$ & Involvement $25-50 \%$ & Involvement $>50 \%$ \\
\hline Unilateral ground-glass opacity & $8(11.0)$ & $8(100.0)$ & $0(0.0)$ & $0(0.0)$ \\
\hline Bilateral ground-glass opacity & $58(79.5)$ & $36(62.1)$ & $16(27.6)$ & $4(6.9)$ \\
\hline \multicolumn{5}{|c|}{ Discharge $(n=49)$} \\
\hline Unilateral ground-glass opacity & $4(8.1)$ & $4(100.0)$ & 0 & 0 \\
\hline Bilateral ground-glass opacity & $41(83.6)$ & $20(48.7)$ & $12(29.2)$ & $9(21.9)$ \\
\hline & \multicolumn{2}{|r|}{ Admission } & \multicolumn{2}{|c|}{ Discharge } \\
\hline Clear & \multicolumn{2}{|r|}{$5(6.8)$} & \multicolumn{2}{|c|}{$2(4.0)$} \\
\hline Inflammatory nodules & \multicolumn{2}{|r|}{$14(19.2)$} & \multicolumn{2}{|c|}{$11(22.4)$} \\
\hline Pleural effusion & \multicolumn{2}{|r|}{$3(4.1)$} & \multicolumn{2}{|c|}{$3(6.1)$} \\
\hline
\end{tabular}

TABLE 3: Laboratory tests.

\begin{tabular}{|c|c|c|c|c|c|}
\hline & Total & Hospital internment $( \pm$ SD $)$ & Total & ICU admission after hospital internment $( \pm$ SD $)$ & $p$ value \\
\hline Lymphocyte count & 59 & $1607(686.8)$ & 15 & $768.4(340.4)$ & $<0.001$ \\
\hline Serum creatinine & 57 & $0.88(0.27)$ & 15 & $1.73(1.68)$ & 0.009 \\
\hline Troponin & 38 & $10.9(48.3)$ & 11 & $18.7(26.9)$ & 0.018 \\
\hline Complement C4 & 47 & $44.2(11.5)$ & 9 & $52.4(12.6)$ & 0.040 \\
\hline Interleukin-6 & 18 & $19.09(22.0)$ & 4 & $45.1(32.2)$ & 0.053 \\
\hline CPR & 59 & $50.8(61.3)$ & 13 & $102.6(93.7)$ & 0.007 \\
\hline $\mathrm{LDH}$ & 53 & $541.1(199.1)$ & 11 & $730.3(307.6)$ & 0.057 \\
\hline WBC count & 59 & $6620.8(3236.8)$ & 15 & $5905.3(1586.0)$ & 0.804 \\
\hline Creatine kinase & 51 & $120.3(188.7)$ & 9 & $180.1(170.7)$ & 0.272 \\
\hline Ferritin & 48 & $559.3(540.2)$ & 12 & $699.0(464.4)$ & 0.244 \\
\hline Bilirubin & 53 & $0.54(0.49)$ & 11 & $0.47(0.15)$ & 0.978 \\
\hline NT-proBNP & 3 & $245.5(341.7)$ & 3 & $899.9(986.9)$ & 0.400 \\
\hline Aspartate transaminase & 54 & $41.3(29.4)$ & 14 & $38.3(14.4)$ & 0.710 \\
\hline Alanine transaminase & 54 & $47.9(34.9)$ & 14 & $44.4(40.7)$ & 0.544 \\
\hline Lactate & 6 & $10.6(1.8)$ & 1 & - & 0.286 \\
\hline D-dimer & 43 & $0.47(0.41)$ & 13 & $0.20(0.99)$ & 0.435 \\
\hline Ammonia & 46 & $33.6(16.2)$ & 8 & $39.6(14.7)$ & 0.233 \\
\hline Vitamin D & 49 & $27.8(12.6)$ & 9 & $24.8(7.7)$ & 0.822 \\
\hline Complement C3 & 47 & $150.8(37.3)$ & 9 & $139.8(24.5)$ & 0.299 \\
\hline Complement $\mathrm{CH} 50$ & 39 & $203.0(57.2)$ & 9 & $191.5(49.4)$ & 0.716 \\
\hline Immunoglobulin $\mathrm{E}$ & 46 & $115.8(150.8)$ & 9 & $124.3(109.9)$ & 0.467 \\
\hline Immunoglobulin A & 47 & $253.7(105.0)$ & 9 & $216.0(84.2)$ & 0.284 \\
\hline Immunoglobulin $\mathrm{M}$ & 47 & $122.0(71.8)$ & 9 & $107.1(73.6)$ & 0.366 \\
\hline Immunoglobulin $\mathrm{G}$ & 47 & $1107.3(369.8)$ & 9 & $989.5(210.5)$ & 0.337 \\
\hline Triglycerides & 44 & $145.6(90.6)$ & 8 & $132.7(62.4)$ & 0.852 \\
\hline Total cholesterol & 43 & $158.4(39.5)$ & 8 & $137.1(31.8)$ & 0.112 \\
\hline Neutrophils & 59 & $4198.5(2781.2)$ & 15 & $4267.4(1465.7)$ & 0.424 \\
\hline Eosinophils & 59 & $57.7(79.3)$ & 15 & $30.2(48.5)$ & 0.233 \\
\hline Platelets & 59 & $161498(47357)$ & 15 & $134580(44249.9)$ & 0.108 \\
\hline Alkaline phosphatase & 49 & $77.3(35.8)$ & 7 & $75.8(36.7)$ & 0.790 \\
\hline Fibrinogen & 21 & $505.0(150.0)$ & 5 & $562.8(136.6)$ & 0.224 \\
\hline Cortisol & 44 & $19.05(11.6)$ & 5 & $23.3(15.6)$ & 0.357 \\
\hline Gamma-glutamyltransferase & 50 & $77.5(77.2)$ & 9 & $97.6(64.2)$ & 0.177 \\
\hline Zinc & 38 & $83.4(15.1)$ & 6 & $74.4(20.6)$ & 0.514 \\
\hline Prothrombin time & 44 & $13.9(3.7)$ & 6 & $13.4(0.59)$ & 0.738 \\
\hline Albumin & 41 & $3.7(0.48)$ & 6 & $3.8(0.45)$ & 0.697 \\
\hline Glycemia & 47 & $126.4(74.5)$ & 8 & $138.1(59.9)$ & 0.242 \\
\hline ACE & 42 & $36.1(17.6)$ & 6 & $35.3(14.8)$ & 0.999 \\
\hline $\mathrm{pO} 2$ & 55 & $73.3(13.4)$ & 14 & $79.8(22.8)$ & 0.687 \\
\hline CD8 cell count & 15 & $382.3(147.7)$ & 3 & $265.3(105.5)$ & 0.250 \\
\hline
\end{tabular}

SD: standard deviation; $n$ (\%); $p$ values were calculated by the Mann-Whitney $U$ test, $\chi 2$ test, or Fisher's exact test. CRP: C-reactive protein; LDH: lactate dehydrogenase; WBC count: white blood cell count; NT-proBNP: N-terminal prohormone of brain natriuretic peptide; ACE: angiotensin-converting enzyme: $\mathrm{pO}_{2}$ : partial pressure of oxygen. 
TABLE 4: Medications taken before admission and chest CT severity at admission compared to the patient's evolution to the ICU.

\begin{tabular}{|c|c|c|c|}
\hline & Hosp_Intern $(n=59)$ & ICU $(n=15)$ & $p$ value \\
\hline \multicolumn{4}{|l|}{ Used medications } \\
\hline Ceftriaxone & $17(23.0)$ & $7(9.5)$ & 0.223 \\
\hline Hydroxychloroquine & $34(45.9)$ & $6(8.1)$ & 0.221 \\
\hline Azithromycin & $52(70.3)$ & $14(18.9)$ & 0.563 \\
\hline Ivermectin & $27(36.5)$ & $11(14.9)$ & 0.056 \\
\hline Enoxaparin & $25(33.8)$ & $8(10.8)$ & 0.446 \\
\hline Chlorpromazin & $16(21.6)$ & $6(8.1)$ & 0.355 \\
\hline \multicolumn{4}{|l|}{ Chest CT findings } \\
\hline Bilateral ground-glass opacity & $43(58.9)$ & $15(20.5)$ & 0.030 \\
\hline Unilateral ground-glass opacity & $8(11.0)$ & $0(0.0)$ & \\
\hline \multicolumn{4}{|l|}{ Chest CT gravity } \\
\hline Involvement $25-50 \%$ & $12(16.4)$ & $4(5.5)$ & 0.027 \\
\hline Involvement $>50 \%$ & $1(1.4)$ & $3(4.1)$ & \\
\hline Pleural effusion & $1(1.4)$ & $2(2.7)$ & \\
\hline \multicolumn{4}{|l|}{ Chest CT nongravity } \\
\hline Clear & $6(8.2)$ & $0(0.0)$ & \\
\hline Involvement $<25 \%$ & $38(52.1)$ & $6(8.2)$ & \\
\hline Nodules & $14(19.2)$ & $0(0.0)$ & \\
\hline Length of stay (days) & $6.2( \pm \mathrm{SD}: 2.7)$ & $10.7( \pm$ SD: 8.7$)$ & $<0.001$ \\
\hline
\end{tabular}

$n$ (\%); $p$ values were calculated by the Mann-Whitney $U$ test, $\chi 2$ test, or Fisher's exact test.

\section{Discussion}

The evaluation of patients admitted to hospital with COVID19, confirmed by diagnostic tests, allows the prediction of risk factors associated with a worse prognosis and consequent evolution to ICU and/or death. Early recognition of high-risk patients can guarantee intensive clinical care directed by the multidisciplinary team in order to monitor, avoid, and control possible complications, such as ARDS, organ dysfunctions, and the need for mechanical ventilation $[9,10]$.

Well-established independent predictors, such as advanced age $(66.5 \pm 17.3 ; p=0.001)$, underlying heart disease, and COPD were also found in our study when we compared hospitalized patients who did not progress with those who progressed to the ICU and/or death $[5,6]$. Due to the reduced $n$ of the research, some data, also defined in the literature, showed only a tendency towards statistical significance for a poor prognosis, such as hypertension $(p=0.064)$ and tachypnea on admission $(p=0.051)$ [5-7].

However, unlike the studies by Minotti et al. [11], Roncon et al. [12], and Zhang et al. [13], our research did not define a statistical relationship or even a trend between male gender, white ethnicity, type 2 diabetes mellitus (DM2), asthma, and immunosuppression with worse clinical prognosis. There was also no significant difference in relation to the prognosis when comparing the groups of hospitalized patients who progressed and those who did not progress to ICU and/or death, with other clinical symptoms such as odynophagia, tachycardia, and fever. Again, it could be owing to the small $n$ of our research but could also demonstrate how nonspecific signals/symptoms such as odynophagia and fever are calling attention to a possible inadequacy of the use of these predictors for screening, for example.

Despite all the scientific limits of a small study, when relevant results are shown and can be easily ratified by similar findings in the literature, we must consider these parameters-advanced age, underlying heart disease, COPD, hypertension, and tachypnea on admission-for the screening of high-risk hospitalized patients in order to try to avoid ICU admission rates even more highly than we are seeing [14-16]. Another fundamental point in the development of a clinical score is the possibility of accurately managing patients uniformly identified in different medical settings.

Evaluating the link between the use of several medications-ivermectin, hydroxychloroquine, ceftriaxone, azithromycin, chlorpromazine, enoxaparin-and a better clinical evolution, no statistical prognostic value was found in accordance with previous studies [7, 17, 18]. Instead, a strong relationship $(p=0.056)$ between patients who used ivermectin-an antiparasitic drug that has shown partial antiviral properties in high-dose in vitro studies-and evolved poorly when compared to those who took the medication and did not worsen clinically was noteworthy. It should be noted, over again, that such results may be justified by the bias inherent in the research design and by the widespread misuse of this medication in our setting, which has its adverse effects well described and its effectiveness for COVID-19 indeterminate by large clinical trials, boosting its risks rather than its benefits $[19,20]$.

In relation to laboratory analysis, among the different tests requested from patients admitted to our service, lymphopenia $(768.4 \pm 340.4 ; p<0.001)$, elevation in $\mathrm{Cr}$ $(1.73 \pm 1.68 ; p=0.009)$, increase in troponin $(18.7 \pm 26.9$; $p=0.018)$, and increase in complement C4 (52.4 \pm 12.6 ; $p=0.04)$ were shown to be statistically significant as predictors of a worse prognosis. A trend towards significance was found with an increase in $\mathrm{LDH}(730.3 \pm 307.6$; $p=0.057)$, elevated IL-6 $(45.1 \pm 32.2$. $p=0.053)$, and increased CRP $(102.6 \pm 93.7 . p=0.053)$. Such results comply with Hou et al. [21], Liu et al. [22], and Zhang et al. [23] 
proposed in their studies. Differently, serum albumin, D-dimer, ferritin, proBNP, and absolute CD8 + cell count were not relevant in predicting the evolution to ICU and/or death $[24,25]$.

As for image evaluation, our data showed that inpatients with extensive opacifications ( $>25 \%$ ), regardless of laterality or the presence of associated pleural effusion, have a worse prognosis $(p=0.027)$. However, when comparing unilateral ground-glass involvement with the bilateral pattern, it proved to be more statistically related to the evolution to ICU and/or death than that $(p=0.03)[26,27]$. It is interesting to highlight that, until the moment of this analysis, patients admitted with opacifications to chest CT at admission and who were later discharged from the hospital still had pulmonary involvement on the image despite evident clinical improvement [28]. The length of staying of those who progressed to the ICU (10.7 \pm 8.7 days) was significantly longer $(p<0.001)$ than those who did not progress with clinical worsening (6.2 \pm 2.7 days) [29].

\section{Conclusions}

Thus, the study in question is established as a pilot project for the creation of scales that can predict the evolution of a patient in an inpatient unit to the ICU. It is evident that the presence of some laboratory markers, clinical criteria, and findings in imaging studies as elucidated in the study may have a significant relationship with the patient's evolution to the ICU.

Therefore, controlled studies with a larger number of patients are necessary in order to establish probable criteria that assess the patient's prognosis in view of the importance of more evidence covering COVID-19 infection given the current situation of the global pandemic.

\section{Data Availability}

The data used to support the findings of this study are restricted by the Research Ethics Committee (Opinion No. 4.080.157, Santa Casa de Misericordia de Juiz de Fora/MG) in order to protect patient privacy. Data are available from Víctor de Oliveira Costa (e-mail: victordeoliveiracosta82@ gmail.com) for researchers who meet the criteria for access to confidential data.

\section{Conflicts of Interest}

The authors declare that there are no conflicts of interest regarding the publication of this article.

\section{References}

[1] K. V. M. S. Noronha, G. R. Guedes, C. M. Turra et al., "Pandemia por COVID-19 no Brasil: análise da demanda e da oferta de leitos hospitalares e equipamentos de ventilação assistida segundo diferentes cenários," Public Health, vol. 36, no. 6, p. 2, 2020.

[2] Ministry of Health, Coronavirus Brasil, Ministry of Health, Brazil, 2020, https://covid.saude.gov.br/.\%20Acessado\% $20 \mathrm{em}$.
[3] World Health Organization, WHO Coronavirus Disease (COVID-19) Dashboard, World Health Organization, Geneva. Switzerland, 2020, https://covid19.who.int/.\% 20Acessado\%20em.

[4] Syria Charitable Association, Protocolo Institucional Atendimento ao Paciente com Suspeita ou Confirmação de COVID19, Syria Charitable Association, Syria. Damascus, 2020, https://www.hcor.com.br/wp-content/uploads/2020/06/ protocolo_atendimento_coronavirus_v12.pdf.

[5] J. Yang, Y. Zheng, X. Gou et al., "Prevalence of comorbidities and its effects in patients infected with SARS-CoV-2: a systematic review and meta-analysis," International Journal of Infectious Diseases, vol. 94, pp. 91-95, 2020.

[6] J. B. Galloway, S. Norton, R. D. Barker et al., "A clinical risk score to identify patients with COVID-19 at high risk of critical care admission or death: an observational cohort study," Journal of Infection, vol. 81, no. 2, pp. 282-288, 2020.

[7] Z. Zheng, F. Peng, B. Xu et al., "Risk factors of critical \& mortal COVID-19 cases: a systematic literature review and meta-analysis," Journal of Infection, vol. 81, no. 2, pp. e16-e25, 2020 Aug.

[8] Ministry of Health, Secretaria de Vigilância em saúde. Boletim Epidemiológico Especial: Doença Pelo Coronavírus COVID-19, Ministry of Health, Brazil, 2020, https://www.gov.br/saude/ pt-br/assuntos/boletins-epidemiologicos-1/set/boletimepidemiologico-covid-32-final-23-09_18h30.pdf.

[9] J. E. Rod, O. Oviedo-Trespalacios, and J. Cortes-Ramirez, "A brief-review of the risk factors for covid-19 severity," Revista de Saúde Pública, vol. 54, p. 60, 2020.

[10] Z. Zhao, A. Chen, W. Hou et al., "Prediction model and risk scores of ICU admission and mortality in COVID-19," PLoS One, vol. 15, no. 7, Article ID e0236618, 2020.

[11] C. Minotti, F. Tirelli, E. Barbieri, C. Giaquinto, and D. Donà, "How is immunosuppressive status affecting children and adults in SARS-CoV-2 infection? A systematic review," Journal of Infection, vol. 81, no. 1, pp. e61-e66, 2020.

[12] L. Roncon, M. Zuin, G. Rigatelli, and G. Zuliani, "Diabetic patients with COVID-19 infection are at higher risk of ICU admission and poor short-term outcome," Journal of Clinical Virology, vol. 127, Article ID 104354, 2020.

[13] J. Zhang, X. Wang, X. Jia et al., "Risk factors for disease severity. unimprovement. and mortality in COVID-19 patients in Wuhan. China," Clinical Microbiology and Infection, vol. 26, no. 6, pp. 767-772, 2020.

[14] F. Gude, V. Riveiro, N. Rodríguez-Núñez et al., "Development and validation of a clinical score to estimate progression to severe or critical state in COVID-19 pneumonia hospitalized patients," Scientific Reports, vol. 10, no. 1, Article ID 19794, 2020.

[15] I. Huespe, I. Carboni Bisso, S. Di Stefano, S. Terrasa, N. A. Gemelli, and M. Las Heras, "COVID-19 Severity Index: a predictive score for hospitalized patients," Medicina Intensiva, vol. S0210-5691, no. 20, pp. 30396-X, 2020.

[16] Worldometer, Worldometers Coronavirus, Brazil, https:// www.worldometers.info/coronavirus/country/brazil/.

[17] D. Giammaria and A. Pajewski, "Can early treatment of patients with risk factors contribute to managing the COVID19 pandemic?" Journal Global Health, vol. 10, no. 1, Article ID 010377, 2020.

[18] A. B. Cavalcanti, F. G. Zampieri, R. G. Rosa et al., "Coalition covid-19 Brazil I investigators. Hydroxychloroquine with or without azithromycin in mild-to-moderate covid-19," The New England Journal of Medicine, vol. 383, no. 21, 2020. 
[19] National Institutes of Health, COVID-19 Treatment Guidelines, National Institutes of Health, Bethesda. MA. USA, 2021, https://www.covid19treatmentguidelines.nih.gov/antiviraltherapy/ivermectin/.

[20] Brazilian Society of Tropical Medicine, COVID-19 e o Paradigma da Medicina Baseada em Fantasia, Brazilian Society of Tropical Medicine, Brazil, 2021, https://www.sbmt. org.br/portal/covid-19-e-o-paradigma-da-medicina-baseadaem-fantasia/?locale $=$ en-US\&lang=en.

[21] W. Hou, W. Zhang, R. Jin, L. Liang, B. Xu, and Z. Hu, "Risk factors for disease progression in hospitalized patients with COVID-19: a retrospective cohort study," Infectious Diseases, vol. 52, no. 7, pp. 498-505, 2020.

[22] X. Liu, H. Zhou, Y. Zhou et al., "Risk factors associated with disease severity and length of hospital stay in COVID-19 patients," Journal of Infection, vol. 81, no. 1, pp. e95-e97, 2020.

[23] Z.-L. Zhang, Y.-L. Hou, D.-T. Li, and F.-Z. Li, "Laboratory findings of COVID-19: a systematic review and meta-analysis," Scandinavian Journal of Clinical and Laboratory Investigation, vol. 80, no. 6, pp. 441-447, 2020.

[24] T. P. Velavan and C. G. Meyer, "Mild versus severe COVID19: laboratory markers," International Journal of Infectious Diseases, vol. 95, pp. 304-307, 2020.

[25] F. Zhou, T. Yu, R. Du et al., "Clinical course and risk factors for mortality of adult inpatients with COVID-19 in Wuhan. China: a retrospective cohort study," The Lancet, vol. 395, no. 10229, pp. 1054-1062, 2020.

[26] E. Abbasi-Oshaghi, F. Mirzaei, F. Farahani, I. Khodadadi, and H. Tayebinia, "Diagnosis and treatment of coronavirus disease 2019 (COVID-19): laboratory. PCR. and chest CT imaging findings," International Journal of Surgery, vol. 79, pp. 143$153,2020$.

[27] M. Francone, F. Iafrate, G. M. Masci et al., "Chest CT score in COVID-19 patients: correlation with disease severity and short-term prognosis," European Journal of Radiology, vol. 30, pp. 1-10, 2020.

[28] X. Ding, J. Xu, J. Zhou, and Q. Long, "Chest CT findings of COVID-19 pneumonia by duration of symptoms," European Journal of Radiology, vol. 127, p. 109009, 2020.

[29] E. M. Rees, E. S. Nightingale, Y. Jafari et al., "COVID-19 length of hospital stay: a systematic review and data synthesis," BMC Medicine, vol. 18, no. 1, p. 270, 2020. 